\title{
创新设计竞争力战略研究
}

\author{
“创新设计竞争力研究”综合组
}

\begin{abstract}
摘要: 本文以我国从 “制造大国” 向 “创造大国” 转变的战略需求出发, 阐述了在知识网络时代背景下, 设计 3.0 的特征、 趋势和价值, 以及创新设计竞争力的内涵及要素; 并以效益、设计能力和设计环境三项指标为基础, 构建国家创新设计竞争 力、城市创新设计竞争力和企业创新设计竞争力三位一体的设计竞争力评价体系, 采用一些国家、城市和企业的数据样本分 类开展试点评估，在此基础上总结得出提升我国创新设计竞争力的政策建议和具体措施。
\end{abstract}

关键词: 设计 3.0 ; 创新设计; 设计竞争力

中图分类号: T19 文献标识码: A

\section{Research on a Competitive Strategy for Innovative Design in China}

\author{
The Research Group of the Innovation Design Competitiveness
}

\begin{abstract}
Based on China's strategic transformation from a manufacturing country into a creative country, this paper outlines the characteristics, trends, and value of Design 3.0 in the era of the knowledge network, and discusses the factors and implications of competitiveness in innovative design. On the basis of the three indices of benefit, design capability, and design environment, these authors construct a three-in-one evaluation system for design competitiveness that comprises national, urban, and enterprise-based competitiveness in innovative design. This study divides various countries, cities, and enterprises into data samples, and carries out a pilot evaluation. The authors then summarize policy recommendations and specific measures to enhance China's innovative design competitiveness.
\end{abstract}

Keywords: Design 3.0; innovative design; design competitiveness

\section{一、前言}

中国工程院于 2013 年 8 月启动了 “创新设计 发展战略研究” 重大咨询项目, 由中国工程院与中 国机械工程学会联合开展, 组织来自全国高等院校、 研究机构和重点企业的 20 多位院士和 100 多位专 家组成项目组, 围绕创新设计的定义和内涵、价值
和作用、发展趋势及关键共性技术等内容开展深入 研究。2015 年 2 月, 《关于大力发展创新设计的建 议》报告作为 “创新设计发展战略研究” 项目重要 成果引起政府的高度重视和社会的广泛关注, “提 高创新设计能力” 作为提升我国制造业创新能力的 重要举措, 被列入 “中国制造 2025 ” 国家战略。“设 计竞争力研究” 咨询项目作为 “创新设计发展战略

收稿日期 : 2017-04-25; 修回日期 : 2017-05-15

联系人 : 徐江, E-mail: xujzju@163.com

资助项目：中国工程院咨询项目 “设计竞争力研究” (2015-XZ-13); 同济大学人文社科青年基金项目 “面向知识网络时代的国家创新设计发 展战略研究” (20160586)

本刊网址：www.enginsci.cn 
研究” 项目研究的延续, 从国家、城市、企业三个 层面进行深入调研和实证分析 $[1,2]$ 。

项目研究指出设计能力作为创新发展程度的重 要衡量标准, 显著提升了国家的综合竞争力, 创新 设计竞争力的评价有助于客观分析各国设计政策及 其产业创新发展状况, 并进行比较和分析。这不仅 对国家综合竞争力的提升有着重要的理论意义，同 时对城市以及企业设计竞争力的提升也有着现实意 义和引领作用。为此, “创新设计竞争力研究” 项 目组在对国内外广泛深入调研的基础上，借鉴国外 现有竞争力指标体系，研究形成的国家、城市、企 业三大创新设计竞争力指标体系，进而在考虑指标 特性、样本差异的基础上, 形成了创新设计竞争力 的层次性指标体系，并以此开展试点评估。

\section{二、创新设计竞争力的内涵}

设计是人类对有目的的创造和创新活动的预先 设想、计划和策划, 是将信息、知识、技术和创意 转化为产品、工艺装备、经营服务的先导和准备, 决定着制造和服务的品质和价值。设计推动了人类 文明的进步，经历了农耕时代的传统设计（表征为 设计 1.0) 和工业时代的现代设计 (表征为设计 2.0), 正跨入知识网络时代的创新设计（表征为设计 3.0) 新阶段（见图 1)。创新设计是对设计的综合拓展， 涵盖工业设计、材料设计、产品设计、工艺设计、 工程设计、服务业态设计等。它以知识网络时代为 背景, 以绿色低碳、网络智能、开放融合、共创分 享等为主要特征, 为产品、产业的全过程提供系统 性服务, 融技术创新、产品创新和服务创新为一体, 是实现科技成果转化、创造市场新需求的核心环节。

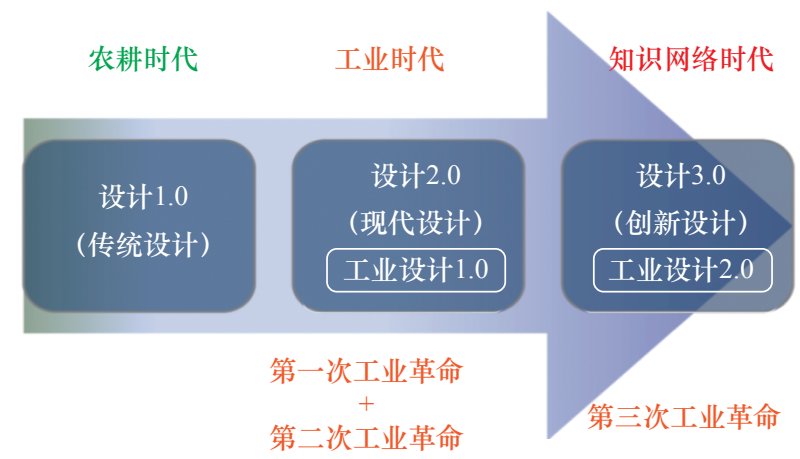

图 1 设计的进化: 传统设计一现代设计一创新设计
创新设计是驱动企业转型升级, 促进经济增长方式 转变, 引领新产业革命, 提升国家核心竞争力的关 键所在 [3 5]。

国家创新设计竞争力已成为衡量一国投资环境 和经济竞争力的主要指数, 城市则是一国的重要组 成单元，提高城市创新设计竞争能力是提高国家创 新设计竞争能力的重要举措。企业是创新设计的实 践主体，也是产业和国家竞争力的基本构成单元。 企业通过培育创新设计能力, 获取外部文化、技 术、商业资源优势，并加以综合利用，其优势主 要体现在经济效益、管理战略和资源禀赋等方面。 因此, 创新设计竞争力研究以国家、城市和企业 在创新设计领域的研发投入、人才培养、公共服 务、品牌价值等为输入要素, 综合衡量依靠创新 设计为竞争手段实现创新能力提升和效益改善。 通过若干样本实证分析验证，构建一整套科学有 效的创新设计竞争力的评价指标体系。

\section{三、创新设计竞争力研究现状}

创新设计竞争力在国家创新体系中具有独特 的地位和作用。自 2002 年以来，首尔市政府、国 际平面设计协会、剑桥大学制造业研究所、香港 设计中心、芬兰赫尔辛基艺术与设计大学、欧洲 工商管院理学院和科技政策研究院等研究机构先 后遴选若干与设计相关的竞争力要素, 如研发投 入、人才培养、公共服务、品牌价值等输入要素, 以及盈利规模、税收水平等输出因素, 开展以国 家、城市为对象的设计竞争力评估（见表 1), 并 相继发布了《全球设计竞争力研究报告》《全球设 计观察》《国际设计记分牌》《亚洲国家设计竞争 力报告》《首尔设计调研》和《香港设计指数》等 多份报告。报告一致指出美国、德国、瑞典等国 家和地区的制造业发达，经济形态多元化，创新 设计竞争力也极强。尤其是芬兰的阿尔托大学设 计创新中心发布了全球的设计竞争力排名, 我国 设计竞争力全球排名为第 35 位，低于我国当年度 全球竞争力排名的第 29 位。综合来看，设计竞争 力评价研究主要集中在三个方面：一是对设计体 系及设计政策进行深入研究; 二是充分考虑样本 的发展模式、发展现状以及设计系统框架的差异 性; 三是数据采集可得性以及计算的科学性。 
表 1 国内外设计竞争力研究简况及对比分析

\begin{tabular}{|c|c|c|c|c|}
\hline 名称 & 提出机构 & 核心要素 & 特点 & 不足 \\
\hline 首尔设计调研指数 & 首尔市政府 & $\begin{array}{l}\text { - 对设计的政策支持 } \\
\text { - 设计文化环境 / 教育 } \\
\text { 资源 } \\
\text { - 首设计工业状况 }\end{array}$ & $\begin{array}{l}\text { - 指标数量多, 覆盖范 } \\
\text { 围广 } \\
\text { - 定量指标 } \\
\text { - 数据来源广泛、可靠 }\end{array}$ & $\begin{array}{l}\text { - 可操作性偏低, 不适 } \\
\text { 合在地区、国家以及 } \\
\text { 国际范围内使用 } \\
\text { - 设计政策类指标难以 } \\
\text { 实现 }\end{array}$ \\
\hline 亚洲设计调研指数 & $\begin{array}{l}\text { 国际平面设计协会和首 } \\
\text { 尔市政府 }\end{array}$ & $\begin{array}{l}\text { - 各城市设计政策、设 } \\
\text { 计工业、设计教育和 } \\
\text { 设计文化的现状对比 }\end{array}$ & $\begin{array}{l}\text { - 指标精简, 可操作 } \\
\text { 性高 } \\
\text { - 公开数据定量评价和 } \\
\text { 描述性指标定性分析 } \\
\text { 相结合 }\end{array}$ & $\begin{array}{l}\text { - 定性指标不灵敏, 没 } \\
\text { 有体现城市间差距 } \\
\text { - 调研数据不完整 }\end{array}$ \\
\hline 国际设计记分牌 & 剑桥大学制造业研究所 & $\begin{array}{l}\text { - 各国设计政策环境 } \\
\text { - 各国设计教育投入 } \\
\text { - 各国设计商业产出和 } \\
\text { 收益 }\end{array}$ & $\begin{array}{l}\text { - 定量指标, 数据容易 } \\
\text { 获得, 可操作性高 } \\
\text { - 采用绝对和相对指 } \\
\text { 标, 使国家间对比更 } \\
\text { 加合理 }\end{array}$ & $\begin{array}{l}\text { - 国家政策类数据难以 } \\
\text { 获得 }\end{array}$ \\
\hline 香港设计指数 & 香港设计中心 & $\begin{array}{l}\text { - 香港设计人力资源和 } \\
\text { 相关行业投资 } \\
\text { - 产业架构和市场需求 } \\
\text { - 社会文化和知识产权 } \\
\text { 环境 }\end{array}$ & $\begin{array}{l}\text { - 指标体系全面、细致 } \\
\text { - 指标的设立旨在体现 } \\
\text { 和提升设计的社会公 } \\
\text { 认度 }\end{array}$ & $\begin{array}{l}\text { - 指标划分过多, 拘泥 } \\
\text { 于细节 } \\
\text { - 指标实用性不广泛 }\end{array}$ \\
\hline 全球设计观察 & $\begin{array}{l}\text { 芬兰赫尔辛基艺术与设 } \\
\text { 计大学 }\end{array}$ & $\begin{array}{l}\text { - 设计产业发展和市场 } \\
\text { 范围 } \\
\text { - 公司研发投入和生产 } \\
\text { 过程 } \\
\text { - 产业价值链和顾客 } \\
\text { 导向 }\end{array}$ & $\begin{array}{l}\text { - 侧重于设计产业竞争 } \\
\text { 力比较 } \\
\text { - 体现国家竞争力与设 } \\
\text { 计竞争力关系 }\end{array}$ & $\begin{array}{l}\text { - 各指标含义十分抽 } \\
\text { 象, 数据处理复杂 }\end{array}$ \\
\hline 国家创新指数 & 欧洲工商管理学院 & $\begin{array}{l}\text { - 各国设计机构、制度 } \\
\text { 和基础设计建设 } \\
\text { - 各国设计教育与力 } \\
\text { 资本 } \\
\text { - 各国市场状况和创新 } \\
\text { 产出 }\end{array}$ & $\begin{array}{l}\text { - 指标涉及面广泛, 衡 } \\
\text { 量范围全面 } \\
\text { - 注重国家的基础设施 } \\
\text { 和市场状况 }\end{array}$ & $\begin{array}{l}\text { - 指标可操作性低, 需 } \\
\text { 要的数据种类多 }\end{array}$ \\
\hline 创新评价指标 & 科技政策研究院 & - 国家创新的资本投入 & $\begin{array}{l}\text { - 定量比较和定性分析 } \\
\text { 相结合 }\end{array}$ & $\begin{array}{l}\text { - 定性分析指标过于 } \\
\text { 主观 } \\
\text { - 指标含义抽象 }\end{array}$ \\
\hline
\end{tabular}

\section{四、创新设计竞争力评价指标体系}

\section{（一）创新设计竞争力评价指标的构建}

竞争力指标选取的优劣是决定评价体系科学性 强弱的首要因素。创新设计竞争力评价是对国家、 城市、企业创新设计能力的一种综合的测评和分析, 其评价指标体系是全面且复杂的一个综合系统，包 含多个各有侧重、相互关联的评价指标。在这种情 况下, 研究采用内涵解析法、聚类分析、标杆分析 法、因子分析法等开展指标提取, 注重指标内容与 组成、确立因子范畴等, 既有效抽取创新设计竞争 力评价的主要构面, 体现设计 3.0 时代的价值与特 征, 又确保指标体系的规范化、可比性和可操作性,
有针对性地解决国家创新、区域发展、企业转型存 在的突出问题。

创新设计竞争力评价指标体系分为国家、城市 和行业（企业）三个层面, 每个指标体系的建立都 有独立完整的理论基础、研究依据和推进过程。总 体而言, 由文献研究、指标池建立、专家访谈、指 标体系构建、评估与纠正等阶段组成（见图 2)。国 家、城市、企业的创新设计竞争力, 由于其定义、 范畴以及与国家竞争力的关系各有不同, 其指标体 系的构建过程与方法也在共性基础上体现出差异化 特征。根据现有较为完整的评价体系评价因子, 研 究构建了设计竞争力指标池。在指标构建总体原则 指导下, 结合专家的指导意见，对设计竞争力的一 


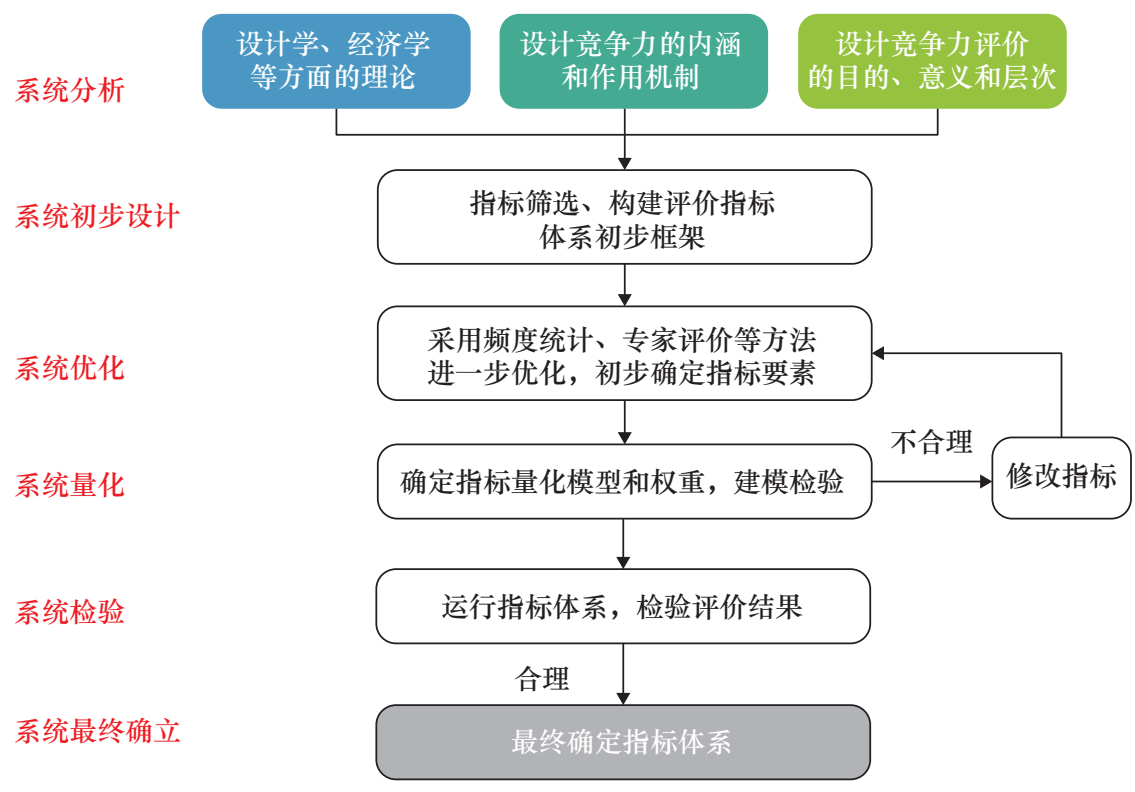

图 2 创新设计竞争力评价指标体系

级指标进行重新篮选和梳理, 研究确定创新设计竞 争力的一级指标体系由效益、设计能力、设计战略 构成。

效益指标主要由与创新设计相关的研发成果、 新产品及新服务模式等表征, 其中研发成果包括 知识密集型产业增加值占世界的比重、重大专利 的贡献量、拥有世界知名品牌的数量、单位价值 全生命周期资源能源消耗强度、市场占有率等指 标; 新产品及新服务模式包括互联网 + 在商业模 式中的占比、产品质量和用户满意度等指标。设 计能力 (潜能) 指标主要由设计教育水平、设计 研发投入、设计技术和工具来表征，其中设计教 育水平包括设计研发投入、设计技术和工具等, 还包括设计人员的增长率、设计师的数量、质量 等指标; 设计研发投入包括研发经费的投入、增 长率、设计投入、设计服务业增加值占 GDP 的比 重等; 设计技术和工具包括数字化设计、工具普 及率、大数据等先进技术的渗透率, 孵化器、实 验室和科技创新园区的数量。设计战略指标主要 由政策支持、设计文化等组成，其中政策支持包 括先进的国家战略、知识产权保护力度、新产品 支持政策等; 设计文化则包括工业创新文化、产 业创新文化等。

\section{（二）国家、城市和企业的设计竞争力评估指标} 由于国家创新设计竞争力、城市创新设计竞争
力和企业创新设计竞争力的定义、范畴各有不同, 因此, 在三个层次指标体系构建过程中, 既保持了 一级指标的共性与协调, 也适当考虑二级和三级指 标的特性和差异。图 3、图 4、图 5 分别是国家、 城市、企业创新设计竞争力指标构成。

\section{五、国家、城市和企业的设计竞争力评估}

\section{（一）国家创新设计竞争力分析}

在国家创新设计竞争力方面, 创新设计对一个 国家经济增长的贡献率随着科技水平的提高呈现递 增趋势。根据世界经济论坛发布的《全球竞争力报 告》, 处于全球竞争力排名前列的芬兰、德国、日本、 美国、瑞士无一不将提升创新设计能力作为提升国 家竞争力的重要手段, 且都建立了创新设计发展战 略体系, 并将之上升到国家战略。国家设计竞争力 的评估样本首先选取了 $\mathrm{G} 20$ 国家，以及芬兰、新加 坡、瑞士三个国家。最终评价出国家设计竞争力排 序如图 6 所示。总体评估排名显示了国家创新设计 竞争力的阵营分类, 即第一阵营为竞争力很高的国 家。美国的优势远远领先于其他样本国家。因其拥有 完善的和开放的市场经济体系, 超一流的科研院所 以及人才储备, 其研发投入及创新转化率也领先于 全球。良好的国内发展环境为创新设计提供了源源 不断的活力, 保证了其创新设计竞争力的领先地位。 德国、芬兰和日本创新设计竞争力评价结果分 


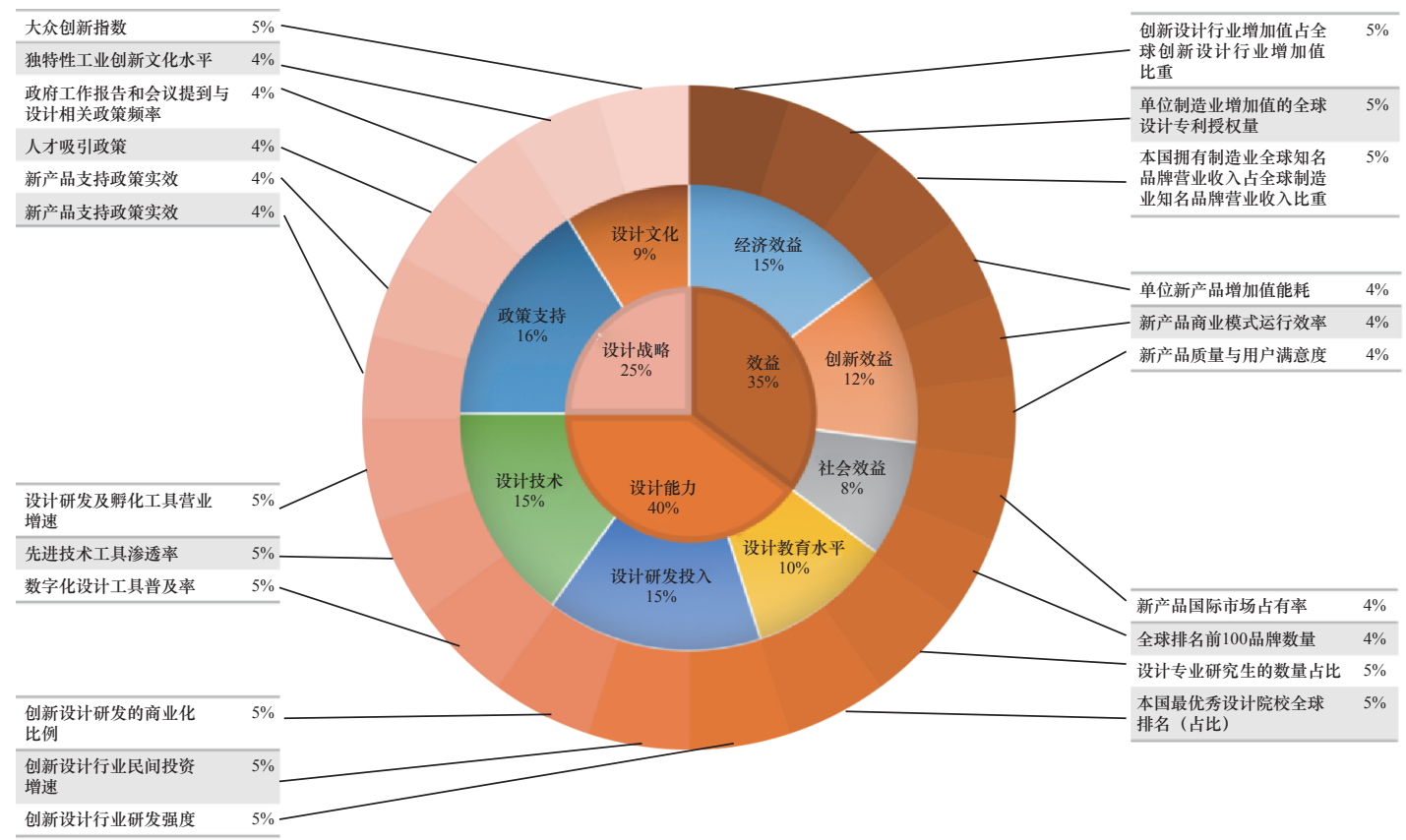

图 3 国家创新设计竞争力的指标构成

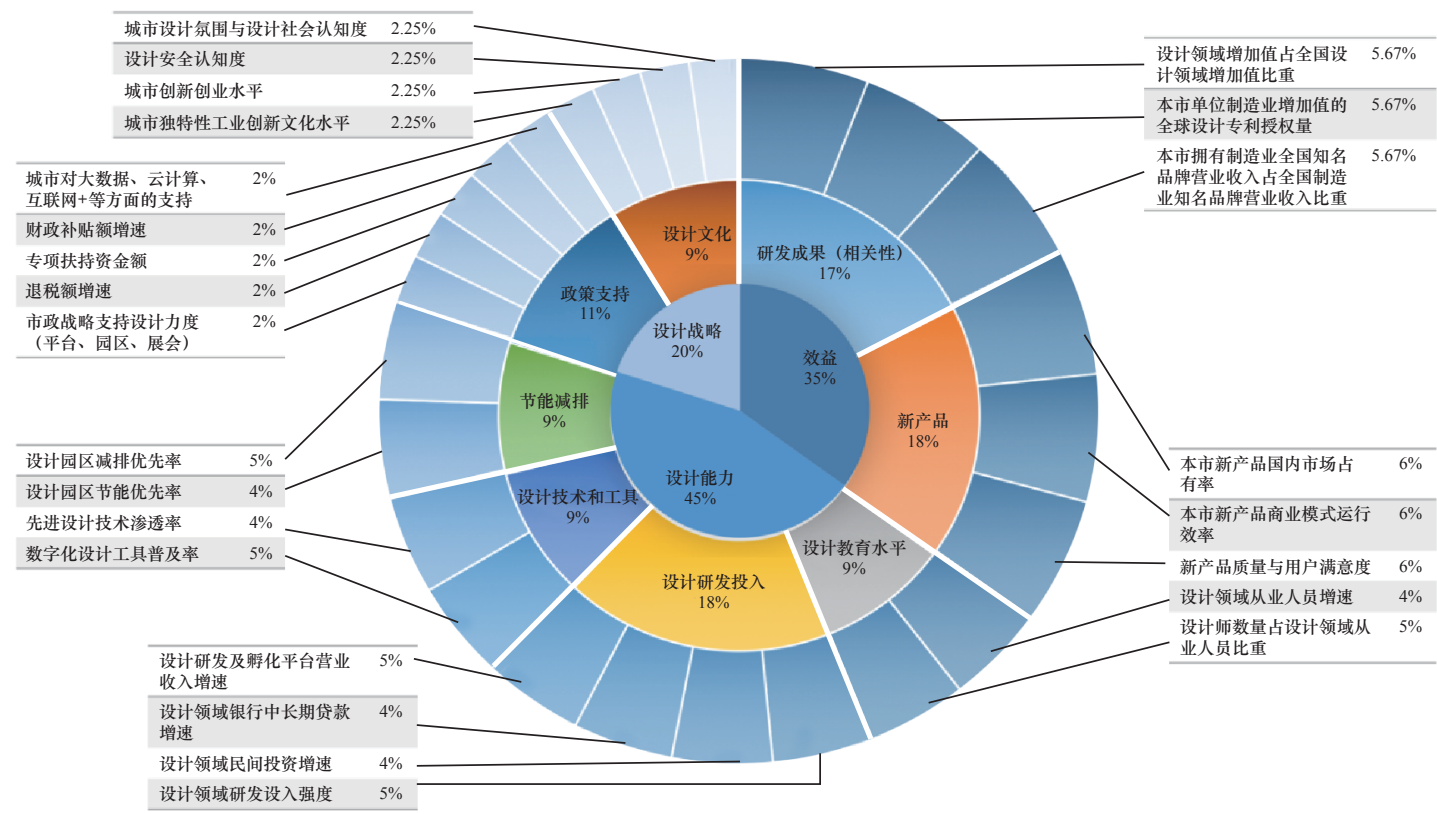

图 4 城市创新设计竞争力的指标构成

数较高, 他们的创新设计发展现状和驱动要素各有 特征，同时位列第二阵营；第三阵营由瑞士、英国、 法国、意大利、韩国、新加坡、加拿大、澳大利亚 组成, 其创新设计竞争力表现良好; 第四阵营为创 新设计竞争力一般的国家, 中国处于这个阵营, 此 阵营还包括俄罗斯、南非、印度、巴西和阿根廷。 在这之后, 还包括创新设计竞争力较低的第五阵营 和创新设计竞争力很低的第六阵营, 分别包括墨西
哥、印度尼西亚、土耳其，以及沙特阿拉伯。除去 欧盟，在此排名中第 1 7 位为优势，排名第 8 14 位为中势，第 15 位之后为劣势。

\section{（二）城市创新设计竞争力分析}

城市创新设计竞争力的研究是在城市不断扩 张、生产力不断进步、经济不断发展的时代背景下 出现的一个新课题。新一轮的技术创新浪潮, 对城 


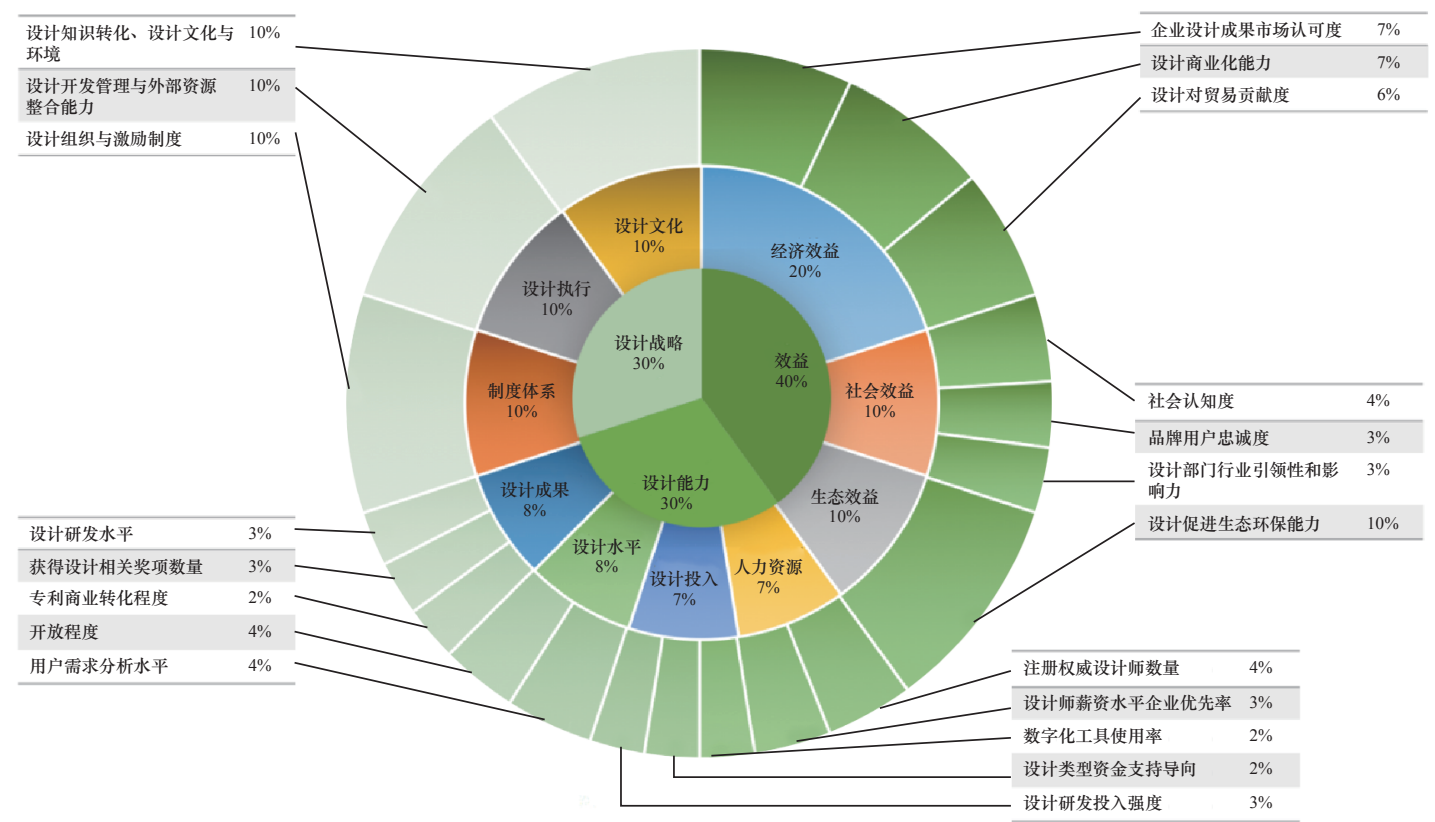

图 5 企业创新设计竞争力的指标构成

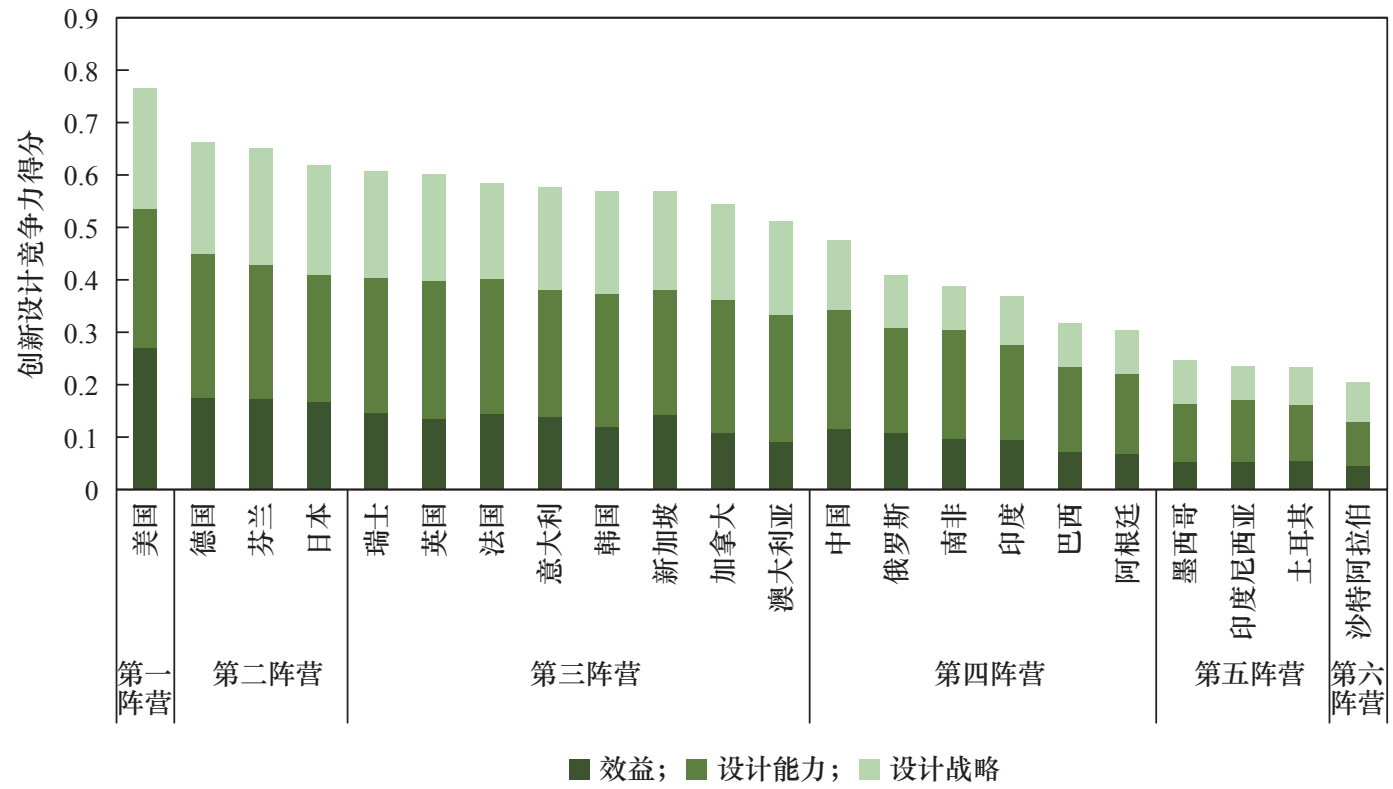

图 6 国家创新设计竞争力得分

市的进一步发展既是艰巨的挑战，也是一种不可多 得的机遇。研究选取的样本城市是以省会和直辖市 为代表的的 32 个国内城市以及以 G20 国家为代表 的主要国外城市。

从效益、设计能力和设计战略的一级指标上 分析国内 32 个城市的创新设计竞争力 (见图 7), 结果显示香港、北京、广州、上海、深圳、杭州 的效益驱动力都十分突出; 属于创新设计能力驱 动型城市有上海、香港、深圳、广州、杭州、北京;
属于创新设计战略驱动型城市有深圳、上海、广 州、杭州、北京、南京、重庆、合肥、成都、西 安等城市。综合各项指标体系的表现, 可以看到 香港、上海、深圳、广州是在三个一级指标表现 中俱佳的城市, 是属于综合驱动力发展十分突出 的城市。

从国外各城市的创新设计竞争力得分来看（见 图 8)，柏林、伦敦、巴黎、罗马、首尔、莫斯科的 发展模式相近, 效益、能力和战略驱动力都比较均 


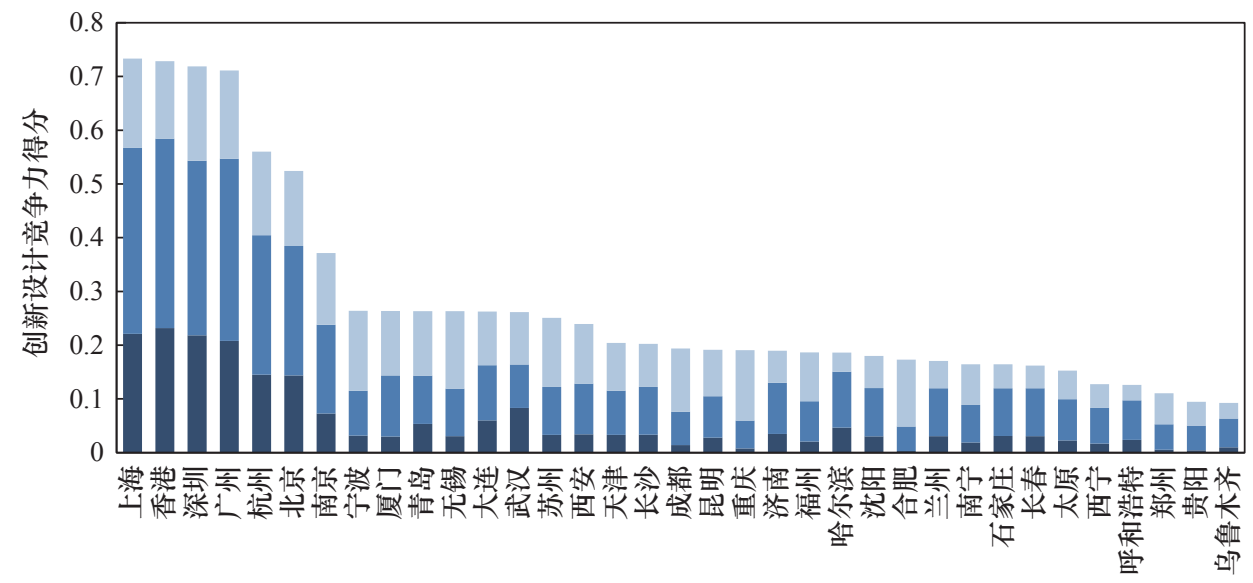

国内城市

口效益; 口设计能力; 设计战略

图 7 国内 32 个城市创新设计竞争力得分

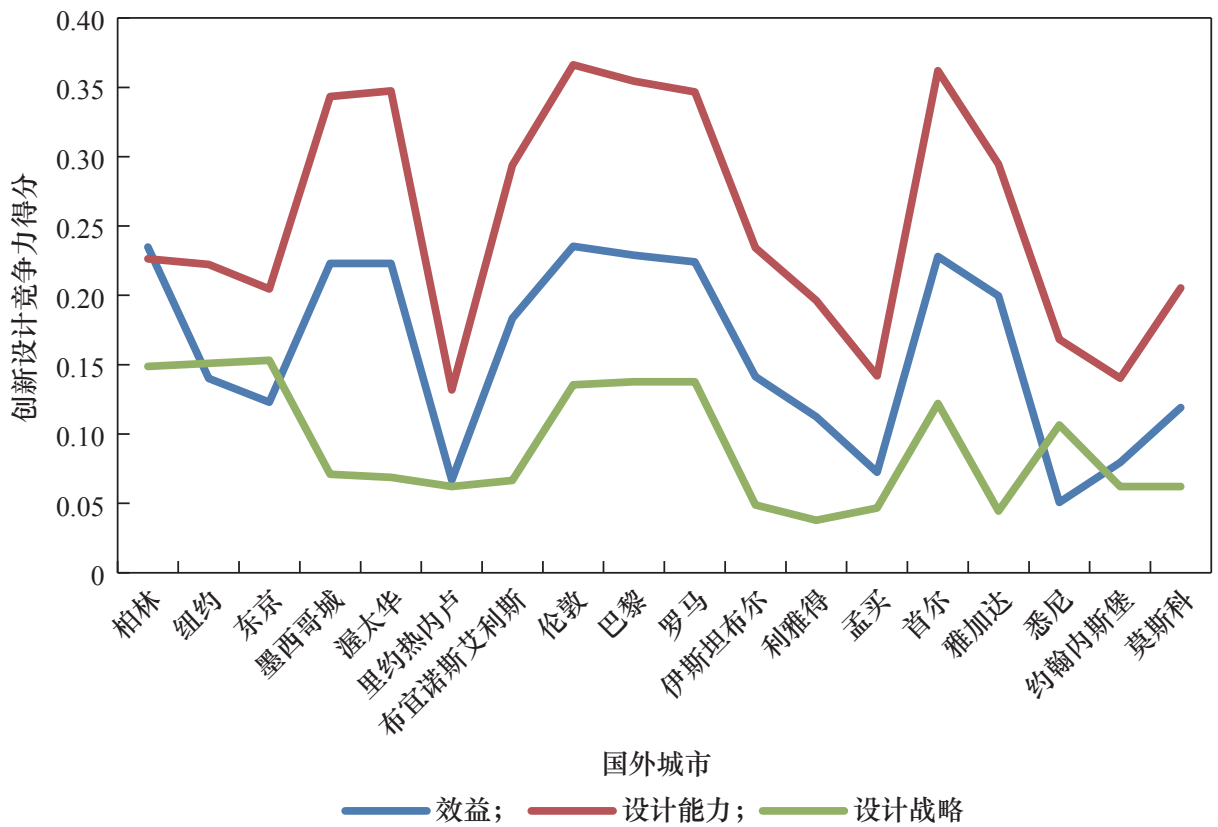

图 8 国外城市创新设计竞争力得分

衡, 墨西哥城和渥太华的战略驱动力较另两个一级 指标要稍弱, 而纽约、东京和悉尼的效益驱动力要 弱于设计能力和设计战略两项指标。通过聚类分析 可以把国内外 50 个城市进行比对, 并归纳为四个 类别。巴黎、首尔、上海、深圳、东京、纽约、北 京和杭州等城市的发展模式类似，效益、能力和战 略驱动力都十分突出, 表明创新设计竞争力在三个 一级指标上的表现均是所有类别中最强的, 为设计 领先型。跟随其后的是两类不同发展驱动力的城市, 一类是墨西哥、雅加达和伊斯坦布尔等的效益能力 驱动型。另一类是以昆明、西安、合肥与悉尼等为
代表的战略驱动型。最后是里约热内卢、孟买、沈 阳、南昌、兰州和哈尔滨等为代表的城市，他们在 三个一级指标上的表现都是最弱的，即待发展型。

\section{（三）企业创新设计竞争力分析}

在 2015 年发布的国家战略《中国制造 2025》中, 创新设计作为 “中国制造 2025” 国家战略的重要组 成部分，在全面提升我国产业国际竞争力和国家竞 争力, 提升我国在全球价值链分工地位, 推动 “三 个转变” 等方面发挥着重要作用。本节基于设计 3.0 视野下的企业创新设计竞争力评价指标, 聚焦工程 
机械、海洋工程装备及船舶、电力装备、家电等重 点领域展开设计竞争力分析与评价。

\section{1. 工程机械企业创新设计竞争力评估}

工程机械行业作为装备制造业的重要组成部分, 是产业关联度高、吸纳就业能力强、技术资金密集、 对国民经济贡献显著的支柱产业之一。我们对国内 7 家典型企业的创新设计竞争力进行了研究, 其企业 创新设计竞争力得分如图 9 所示。徐工集团、三一 重工股份有限公司（简称 “三一重工”）和中联重科 股份有限公司（简称 “中联重科”）是我国最具竞争 力的工程机械企业。在设计效益上, 这三家企业领 先于其他四家企业。在设计能力上，徐工集团、中 联重科和三一重工占据行业前三甲。拥有高水平设 计技术人员是这三家企业在设计能力上领先的主要 原因。在设计战略上，徐工集团获得了同行业第四 位，而中联重科和三一重工表现不佳，分别位于第 六位和第七位。徐工集团通过全球资源协同，在行 业内构建了具有其特色的全球化研发平台 [6]。

2. 海洋工程装备及船舶企业设计竞争力评估

海洋工程装备及船舶行业是关系国防安全及国 民经济发展并推动产业结构升级的战略性产业, 为 国防建设、航运交通、水产渔业和海洋开发等提供 主要装备。选取了 7 家我国主要的海洋工程装备及 船舶类企业进行企业创新设计竞争力的分析和评估 (见图 10)。在设计效益上, 海洋石油工程股份有限 公司（简称 “海油工程”）位居同行业首位，领先 于振华重工（集团）股份有限公司（简称 “振华重
工”) 和中国船舶工业集团公司（简称 “中国船舶”)。 海油工程对外大力开发国际市场, 海外收入占比持 续攀升，首次超过 $30 \%$ 。在设计能力上，中国船舶 和海油工程分别位于行业第二位和第三位，而振华 重工仅位于第五位。中国船舶在设计能力指标上获 得高分得益于其丰硕的设计成果，中国船舶有效发 明专利总量增长 $342 \%$ 。其设计的 “海洋石油 981 ” 号 $3000 \mathrm{~m}$ 深水半潜式钻井平台最大作业水深为 $3050 \mathrm{~m}$, 最大钻井深度为 $12000 \mathrm{~m}$, 主要运行指标 达到国际先进水平。在设计战略上, 振华重工展现 了优秀的设计组织管理能力, 通过 “确立三个项目、 营造四大环境、攻克五大技术” 的手段实现以信息 化促进海洋工程装备事业的跨越式发展的战略目标。

3. 电力装备企业创新设计竞争力评估

电力装备行业是实现能源安全稳定供给和国 民经济持续健康发展的基础行业。研究选取 12 家 我国主要的电力装备类企业, 对设计竞争力进行 分析和评估。在设计效益上, 电力装备行业正面 临产能过剩、市场需求变化的严峻考验。在设计 效益指标上领跑的上海电气集团股份有限公司（简 称 “上海电气”）主动适应经济发展新常态。在设 计能力上，中国西电集团公司（简称 “中国西电”） 领先于上海电气和东方电气集团有限公司（简称 “东方电气”)。高度重视设计人才培养和科技投入 高位运行是中国西电在设计能力上获得高分的基 础, 设计人才和科研经费的投入使得中国西电在 自主创新上收获颇丰，在特高压、柔性输电、新

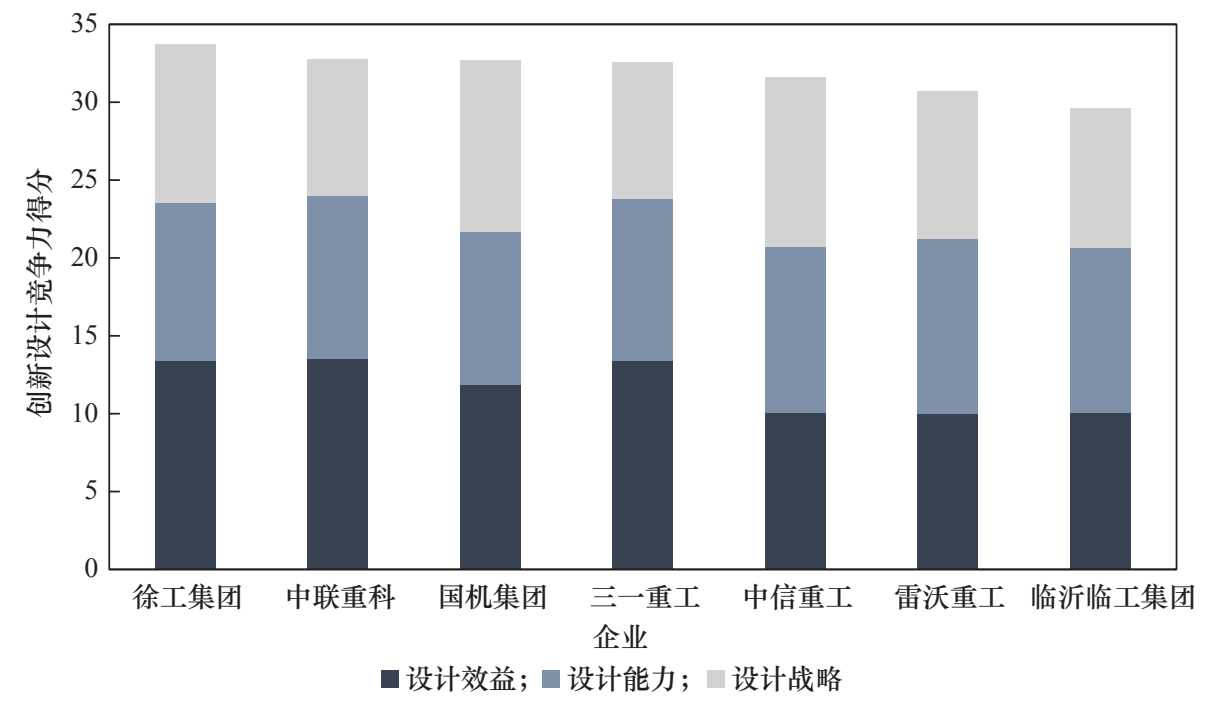

图 9 工程机械企业创新设计竞争力得分 
能源等新业务领域都取得了新突破。在设计战略 上, 指数排行依次是许继集团、白云电气和哈尔 滨电气（见图 11）。

\section{4. 家电企业创新设计竞争力评估}

家电行业是市场化竞争最充分、产业链最完 整、竞争优势最明显的产业之一，不仅在国内市 场拥有极高的市场份额，在全球市场也同样占有 重要比重。在经济新常态下, 家电行业面临严峻 的经济下行压力。产品同质化严重, 品牌差异度 小，技术与功能集成创新贵乏是目前家电行业面 临的主要问题。从供给侧方面来看, 传统高库存 的家电企业, 生产与积压中低端产品, 缺乏中高 端产品的供给, 无法适应消费端的变化, 以致消费
者的购买意愿受到影响。

家电行业各企业在设计效益指标得分上, 行 业前三位分别是格力电器股份有限公司（简称 “格 力”)、美的集团和海尔集团（见图 12）。在国内拥 有极强的品牌影响力和认可度的格力在设计效益指 标上收获了行业最高分。在设计能力上, 格力同样 高居行业首位，展示了企业将培育设计人才作为基 础、掌握关键技术作为核心的设计能力提升策略。 在设计战略上，海尔集团领先于美的集团和格力集 团。海尔启用 “企业平台化、员工创客化、用户个 性化” 的商业模式探索，员工从雇佣者、执行者转 变为创业者、动态合伙人, 以构建社群最佳体验生 态圈, 满足用户的个性化需求。

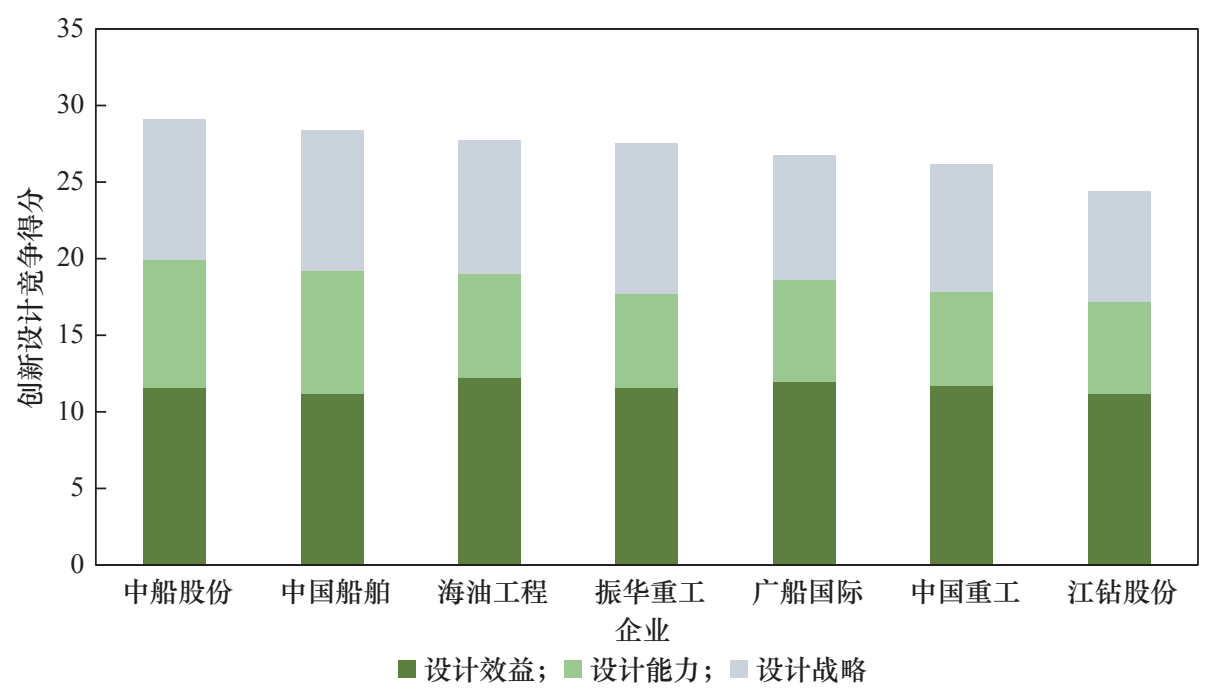

图 10 海洋工程装备及船舶企业创新设计竞争力得分

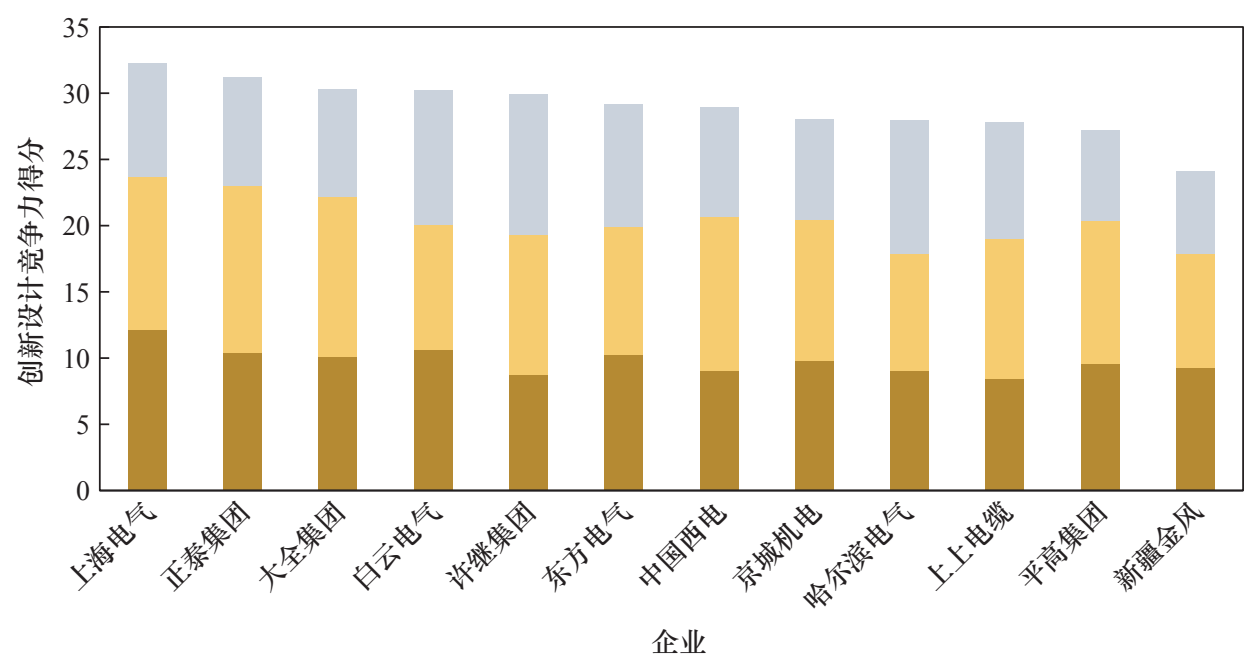

口效益；设计能力；设计战略

图 11 电力装备企业创新设计竞争力得分 


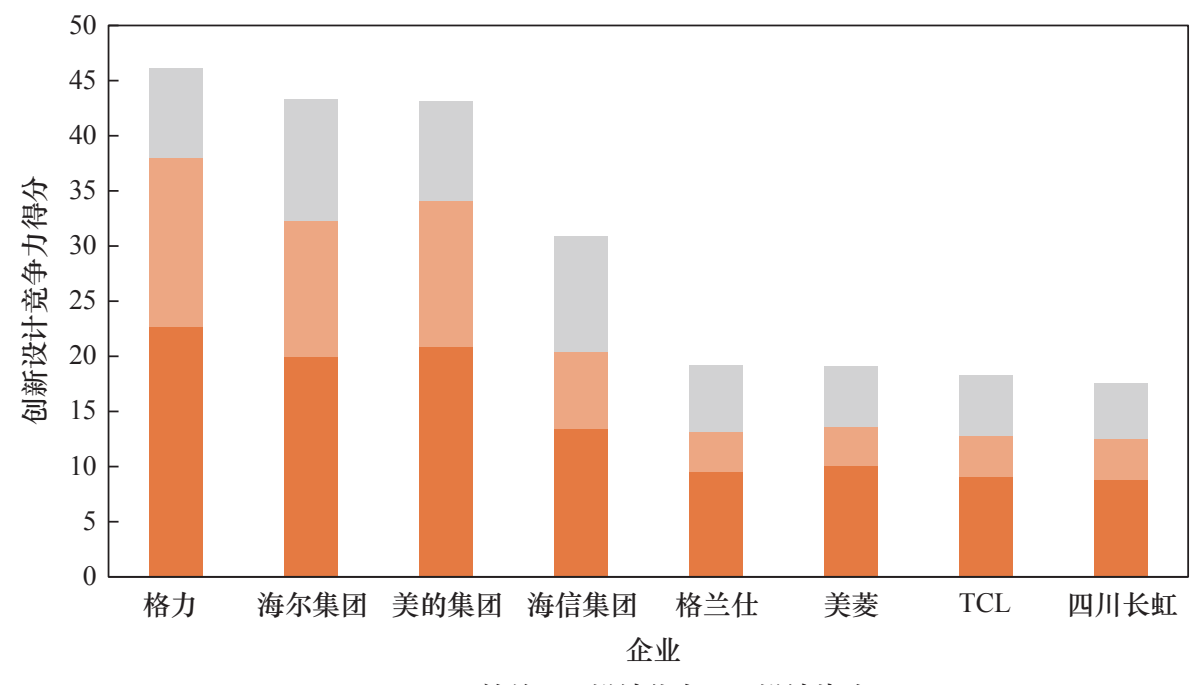

口效益; 设计能力; 回设计战略

图 12 家电企业创新设计竞争力得分

\section{六、提升创新设计竞争力的建议}

提升创新设计能力, 关键在于更新理念、优化 环境、强化基础、改革教育、培育文化, 加快提升 中国创新设计的国际竞争力、可持续发展能力和引 领全球的能力, 研究提出以下五点建议。

(1) 重塑理念。尊重设计规律, 充分认识创新 设计对产品、工艺、经营服务的引领作用，把握创 新设计能力要素和新特征— “绿色低碳、网络智 能、开放融合、共创分享”，引领推动加快实现由 中国制造向中国创造、中国速度向中国质量、中国 产品向中国品牌转变。

（2）优化环境。在创新设计已纳入《中国制造 2025》的基础上, 制定制造业创新设计发展行动纲 要, 完善政策法规环境, 切实保护知识产权, 设计 企业等同高科技企业优惠税率，设计服务进出口实 行零关税。以市场为导向, 改革创新资源配置机制、 权益分享制度、设计评价制度。发挥中国工程院、 机械工程学会、创新设计产业联盟等组织和单位的 引导促进作用，优化以企业为主体、“产学研用金” 协同、军民深度融合的创新环境。开展中国好设计 奖、光华龙腾奖、红星奖等评选以及设计展会、设 计竞赛、设计论坛等活动, 建设设计小镇、设计创 业园区、中外设计园，优化激励大众创业、万众创 新的设计大环境。

（3）强化基础。在持续增加对基础前沿研发投 入, 为自主创新积累知识与技术基础的同时, 各部 门和各单位应加强对创新设计的投入，建立创新设
计基金，强化创新设计人力资本基础。建设认定一 批创新设计技术服务中心等，强化以市场为导向的 创新设计基础技术支撑体系与产业集聚平台。着力 提升先进设计理论、工具和嵌入软件、计算方法和 大数据平台的自主创新、应用普及和资源共享水平, 强化数字化、网络化、智能化、绿色化设计技术基 础，建设世界一流开放共享、高效安全的信息网络 和物理计算环境，积极参与制定国际先进工业标准。

（4）改革设计教育。创新设计源于实践，源于 对市场和社会需求的理解和前瞻。设计教育的首要 任务是引导确立先进科学理念和价值观, 培育创新 创业精神和工匠精神，培育设计创造和实践的兴趣 和自信心，激发人的想象力、创造力。创新设计需 要跨界融合科学技术、经济社会、人文艺术、生态 环境等新知识, 需要分析理解大数据的数学方法和 计算能力, 需要培育、吸引和凝聚跨界人才, 设计 构建共创分享平台网络和机制的能力, 抓紧众筹全 球创新设计资源，创造国际化的教育环境。

（5）构建设计文化。创新设计文化决定创新设 计的特质和品格。在工业化和现代化的进程中，各 国形成了各具特色的设计文化。美国重视基础前沿 研发投入，鼓励自由探索、创新创造，形成创新引 领的设计文化; 德国是后起的制造强国，依靠富有 特色的自然科学、工程与职业教育、先进的工业标 准，形成优质诚信的设计制造文化; 法国、意大利 文化艺术底蕴深厚，孕育优雅华丽的设计文化; 日 本形成了精致实用的设计文化。我国实现向制造强 国跨越，必须培育建设具有中国特色、符合时代要 
求, 尊重创新创造、追求精益求精, 恪守诚信合作、 崇尚共创分享的先进创新设计文化。

\section{参考文献}

[1] 路角祥. 设计的进化与面向未来的中国创新设计 [J]. 装备制造, 2014, 5(6): 5-13.

$\mathrm{Lu}$ Y X. Evolution of design and innovation design for the future China [J]. Equipment Manufacturing, 2014, 5(6): 5-13.

[2] 迈克尔・波特. 国家竞争优势 [M]. 北京: 中信出版社, 2012. Potter M. The competitive advantage of nations [M]. Beijing: CITIC Press Group, 2012.

[3] 路角祥. 创新设计与中国创造 [J]. 全球化, 2015, 5(4):10-13. Lu Y X. Innovation design and Chinese creation [J]. Globalization, 2015, 5(4): 10-13.
[4] 中国工程院重大咨询项目组. 中国创新设计发展战略研究综合 报告 [M]. 北京: 中国科技出版社, 2015.

Major Consulting Project Group of China Academy of Engineering. A comprehensive report on the development strategy of China innovative design [M]. Beijing: China Science and Technology Press, 2015.

[5] 中国机械工程学会. 中国机械工程技术路线图 [M]. 北京: 中国 科学技术出版社, 2011.

Hinese Society of Mechanical Engineering. The roadmap of Chinese mechanical engineering technology [M]. Beijing: China Science and Technology Press, 2011.

[6] 徐江, 刘惠荣, 董占勋. 创新设计2015 案例研究 [M]. 北京: 中国 科学技术出版社, 2015 .

Xu J, Liu H R, Dong Z X. 2015 cases study on innovation design [M]. Beijing: China Science and Technology Press, 2015. 